\title{
Liability of CLARIN Centres as Service Providers: What Changes with the New Directive on Copyright in the Digital Single Market?
}

\author{
Pawel Kamocki \\ Leibniz-Institut für \\ Deutsche Sprache, \\ Germany \\ kamocki@ids- \\ mannheim.de
}

\author{
Erik Ketzan \\ Brikbeck, University \\ of London, United \\ Kingdom \\ eketza01@mail.b \\ bk.ac.uk
}

\author{
Julia Wildgans \\ Leibniz-Institut für \\ Deutsche Sprache/ \\ Mannheim Universi- \\ ty, Germany \\ j.wildgans@goo- \\ glemail.com
}

\author{
Andreas Witt \\ Leibniz-Institut für \\ Deutsche Sprache/ \\ CLARIN ERIC \\ witteids-mann- \\ heim.de
}

\begin{abstract}
Providing online repositories for language resources is one of the main activities of CLARIN centres. The legal framework regarding liability of Service Providers for content uploaded by their users has recently been modified by the new Directive on Copyright in the Digital Single Market. A new category of Service Providers, Online Content-Sharing Service Providers (OCSSPs), was added. It is subject to a complex and strict framework, including the requirement to obtain licenses from rightholders for the hosted content. This paper provides the background and effect of these changes to law and aims to initiate a debate on how CLARIN repositories should navigate this new legal landscape.
\end{abstract}

\section{Introduction}

One of the main activities of CLARIN centres is to provide online services, such as online repositories, to their users. However, the content uploaded by users of such services can sometimes be of infringing nature. Researchers are well aware of the fact that language resources may violate many rules from copyright and related rights (such as the sui generis database right) through data protection, to rules on defamation and hate speech.

The question of liability for hosting content (such as language resources) uploaded by users of scientific repositories has not attracted the attention that it deserves, despite it being occasionally brought up at conferences (Kamocki, 2014). This may be due to the assumption by scientists that someone who merely provides an online service (e.g. stores data) should not be liable for illegal acts of the service's users. Under current rules, this statement is largely true, and this common-sense point of view has been reflected in the normative framework for almost the past twenty years (i.e. from the beginning of the participative Web).

However, under pure law (be it Roman or common law), service providers could be found liable for prejudice caused by the users. In fact, at the most fundamental level liability requires three elements: breach, prejudice and a causal link between the two (causation). If there is a breach of law (e.g. copyright infringement or unlawful processing of personal data) that causes prejudice, this prejudice can causally be linked to the actions of a service provider. For example, if sensitive information related to a person's health or sexual orientation is communicated to millions of Internet users via an Internet service (e.g. Facebook), the prejudice suffered by the victim is in fact directly caused by Facebook who made this information available to its users.

This does not mean that the user is not liable for his actions - he or she can also be sued for damages, but from the victim's perspective, the service provider would usually be a much better target. Not only is the service provider easier to identify, but also, as a company or an institution, it is expected to be more solvent than an individual user, and possibly also more inclined to settle to avoid damage to its reputation.

In order to promote the development of online services, in the last years of the twentieth century, legislators in both the United States (cf. the Digital Millennium Copyright Act 1998) and the European Union (see below) adopted special rules (called Safe Harbors) protecting service providers from liability for illegal ac-

\footnotetext{
This work is licenced under a Creative Commons Attribution 4.0 International Licence. Licence details: http:// creativecommons.org/licenses/by/4.0/

Pawel Kamocki, Erik Ketzan, Julia Wildgans and Andreas Witt 2020. Liability of CLARIN Centres as Service Providers: What Changes with the New Directive on Copyright in the Digital Single Market?. Selected papers from the CLARIN Annual Conference 2019. Linköping Electronic Conference Proceedings 172: 172 48-52.
} 
tions of their users. Without these rules, services like Facebook, Twitter or YouTube, as well as countless others, could not have been developed. Nowadays, however, things are slowly beginning to evolve, especially in Europe, where users feel that they live in a world dominated by huge, seemingly omnipotent service providers such as Google, Amazon or Facebook. For some, it is time to revise the Safe Harbor provisions in order to protect user interests. This tendency has been visible in the case law of the Court of Justice of the European Union (CJEU) since at least 2016. ${ }^{1}$ Another big step in this direction has been made by the recently adopted Directive on Copyright in the Digital Single Market (see below).

In the following sections, we will discuss whether and how this situation may affect smaller service providers, such as CLARIN centres.

\section{Liability of Service Providers from e-Commerce to the Digital Single Market}

In EU law, 'service provider' is defined as any natural or legal person providing an information society service (Article 2(b) od the Directive 2000/31/EC). An information society service is defined as "any service normally provided for remuneration, at a distance, by electronic means and at the individual request of a recipient of services" (art. 1, Directive 2015/1535). A service is provided "at a distance" if the provider and the recipient are not simultaneously present; it is provided "by electronic means" if the sent and received by means of electronic equipment; finally it is provided "at the individual request of the recipient" if the transmission of data is initiated on such request.

Regarding the "normally provided for remuneration" requirement, recital 18 of the e-Commerce Directive further specifies that information society services "in so far as they represent an economic activity, extend to services which are not remunerated by those who receive them, such as those offering on-line information or commercial communications, or those providing tools allowing for search, access and retrieval of data". The CJEU also opts for a broad interpretation of this requirement. ${ }^{2}$

It is therefore safe to assume that the definition of a service provider covers not only commercial providers, but also e.g. Wikipedia (which is 'paid for' by donators, cf. Angelopoulos, p. 10) or publicly-funded research data repositories.

As explained above, service providers can, under certain conditions, benefit from liability exemptions, which allowed online services to thrive in the first two decades of the 21 st century. These exemptions were harmonised by the Directive 2000/31/EC of 8 June 2000 on certain legal aspects of information society services, in particular electronic commerce, in the Internal Market (commonly referred to as the e-Commerce Directive). In 2019, the framework was modified by the Directive on Copyright in the Digital Single Market.

\subsection{Liability of Service Providers in the e-Commerce Directive}

The e-Commerce Directive concerns specifically three types of information society services: mere conduit (art. 12; defined as transmission of information in or provision of access to a network), caching (art. 13; defined as intermediate and temporary storage of information, performed for the sole purpose of making its onward transmission more efficient) and hosting (art. 14). This last category is most relevant for CLARIN Centres.

Hosting is defined as storage of information provided by the user. According to the relevant Safe Harbour provision, a hosting provider is not liable for the stored content if two conditions are cumulatively met:

a) the provider does not have actual knowledge of the illegality of the content AND

b) upon obtaining such knowledge, he acts expeditiously to remove or disable access to the content.

The liability exemption relies therefore on a notice-and-take-down approach: once the provider receives notification (typically from a user) about illegal nature of the content that she hosts, she should act promptly to remove the content from the service. A notification, however, is not the only way (albeit the most common in practice) of acquiring such knowledge - it is also possible that the provider discovers the illegal content through her own investigation, in which case she is also required to remove it promptly.

At the time when the e-Commerce Directive was adopted (2000), hosting providers were mostly merely offering storage space. Nowadays, however, they often play a much more 'active' role in presenting the content - a visitor certainly knows that this particular piece of content is hosted by Facebook, YouTube or Ama-

\footnotetext{
1 CJEU, C-160/15, GS Media, 8 September 2016, where it was ruled that providing links to works constituted communication to the public, and therefore copyright infringement, if the provider knows or ought to know about the fact that the works were placed online without permission from the rightholders - if a link is provided for a profit, this knowledge is presumed.

2 CJEU, C-291/13, Papasavvas, 11 September 2014; in this case, the provider was not remunerated by the recipient, but by income generated by advertisements posted on the website.
} 
zon. While it is possible for an ordinary user to overlook the identity of the content provider, it is usually the service provider who attracts viewers. In other words, with the participative Web, the distinction between the content providers and the service providers became blurred. It is not surprising, therefore, that the liability of the latter is often sought. Faced with the issue of Web 2.0 providers, the CJEU decided to opt for a narrow interpretation of the Safe Harbour provision.

For the CJEU, ${ }^{3}$ in order to qualify for the liability exemption, the Service Provider has to meet the criterion set forth in recital 42 of the e-Commerce Directive, according to which its activity has to be "of a mere technical, automatic and passive nature, which implies that the information society service provider has neither knowledge of nor control over the information which is transmitted or stored". This condition is difficult to apply in practice, and the results of its application may be surprising to some. For example, Google was declared to be eligible for the exemption with regards to the GoogleAds service, despite the fact that it actively assists users in the choice of keywords; 4 on the other hand, eBay was declared ineligible for the exemption inasmuch as it exercised some control over the content, actively optimised its presentation and provided tailored services to some users. ${ }^{5}$ A publisher of an online newspaper was also denied the benefit of the liability exemption, as it could not claim lack of awareness of the hosted content. ${ }^{6}$ Therefore, even though the neutrality requirement set forth by the CJEU may initially seem difficult to meet, its practical interpretation seems to be rather liberal.

This requirement to remain passive can also be criticised for discouraging service providers from taking preventive actions against infringement, for fear of loosing their 'neutrality' and therefore the Safe Harbor privilege (this situation is described as the 'Good Samaritan paradox'; cf. van Ecke).

However, approaches to applying the liability limitation to service providers differ among EU Member States. Germany is, or at least was, one of the most strict. In 2009, the Federal Court of Justice (BGH) developed the doctrine of 'adoption' of content, according to which a provider of a service whose 'core value' is constituted by contents provided by users, and who editorially checks and approves the contents, tags posted contents with his logo and requires the users to grant him extensive re-use rights to the contents, 'adopts' the content as his own. In such a case, the liability exemption cannot apply. Recently, however, the Hamburg court found that YouTube does not 'adopt' the content provided by the users - BGH subsequently referred the case to the CJEU, 7 who should soon deliver its opinion on the question whether YouTube can qualify for the liability exemption or not. In making this decision, the CJEU is not unlikely to be influenced by the new, stricter framework introduced by the DSM Directive (see below), and especially by previous case law which is quite strict for actors who commercially host or provide access to copyright-protected content.

It is important to keep in mind that the Safe Harbour provision only shields hosting providers from liability claims (claims for damages), and not from injunction claims (Article 14(3) of the e-Commerce Directive). Therefore, the providers can still be ordered by a court to remove content.

It should also be noted that Article 15 of the e-Commerce Directive further states that service providers have no general obligation to monitor the content that they store or transmit, or to actively seek facts or circumstances indicating illegal activity.

\subsection{Liability of Service Providers in the New Directive on Copyright in the Digital Single Market}

The new Directive on Copyright in the Digital Single Market (hereinafter: the DSM Directive) introduced a new category of Service Providers called 'online content-sharing Service Providers'. They are defined as providers of services "of which the main or one of the main purposes is to store and give the public access to a large amount of copyright-protected works or other protected subject matter uploaded by its users, which it organises and promotes for profit-making purposes" (art. 2(6)). YouTube is a typical example of such a service.

The liability of online content-sharing service providers (OCSSPs) is subject to very complex and much stricter rules (art. 17, several pages long). Because the DSM Directive is of very recent vintage, there is no consensus yet on how to interpret these new rules, and their detailed analysis would greatly exceed the allowed length of this paper; only some basic observations can be made here.

${ }^{3}$ CJEU, joined Cases C-236/08 to C-238/08, Google France, 23 March 2010

4 idem

${ }^{5}$ CJEU, C-324/09, L’Oréal v. eBay, 12 July 2011; see also Cour de cassation, eBay v. Dior, 11-10.508, 3 May 2012.

${ }^{6}$ CJEU, C-291/13, Papasavvas, 11 September 2014.

7 I ZR 140/15

Selected papers from the CLARIN Annual Conference 2019 
Under the new Directive, the acts of the OCSSPs qualify as communication to the public within the meaning of copyright rules (art. 3 of the Directive 2001/29/CE), and therefore the OCSSP is in principle required to obtain authorisation (a license) from the rightholder (or rightholders) (art. 17(1)). A license obtained by the OCSSP automatically (ex lege) covers subsequent communication to the public by the users of the service, provided that it is carried out for non-commercial purposes (art. 17(2)). From the user point of view this seems to mean that anything found e.g. on Youtube can lawfully be shared for non-commercial purposes, which may potentially affect the creation of language resources (although it remains to be seen how this will be implemented in national laws of the Member States). On the other hand, from the OCSSP perspective, especially those hosting content with multiple rightholders (e.g. language resources), the obligation to obtain a license will be very difficult to fulfil. It is also relevant that the DSM Directive also allows Member States to introduce extended collective licensing mechanisms (art. 12), which could facilitate the process of obtaining licenses, but it is too early to say which Member States will adopt this, and how.

The liability limitation for hosting providers under the e-Commerce Directive does not apply to OCSSPs (art. 17(3)). If the OCSSP fails to obtain a license from rightholders, she is liable for copyright infringement, unless she demonstrates that she made 'best efforts' to obtain the license; to make sure that any content for which she obtained a specific notification from rightholders will not be available via her service; upon receiving a notification from rightholders, to act expeditiously to remove and/or disable access to the notified content; and to prevent future uploads of this content (art. 17(4)). This would probably require close cooperation with rightholders, sophisticated mechanisms of content notification with human review (art. 17(9)), as well as screening of uploaded content (which is why, during the adoption process, the opponents of this solution, originally in art. 13, referred to it as 'censorship machines' (Reda)). This may be seen as a contradiction of the rule of art. 15 of the e-Commerce Directive, which expressly states that service providers shall have no general obligation to monitor content; however, art. 17(8) of the DSM Directive expressly states the new framework "shall not lead to any general monitoring obligation".

It is not yet clear what would constitute 'best efforts' that OCSSPs have to make and demonstrate in order to avoid liability. It seems that the standard will be flexible, taking into account the size of the service, the target audience and the type of material uploaded by users, and the costs of implementation of preventive solutions (art. 17(5)). A CLARIN Centre, if it qualifies as an OCSSP (see below), would probably be held to a significantly lower standard than YouTube.

Importantly, art. 17 of the DSM Directive takes into account some copyright exceptions and limitations (art. 17(7)). For example, if a video was made and uploaded by a user within the limits of parody, then the content, even if notified by the rightholder, should not be removed. Limiting the users' rights to rely on exceptions for parody and pastiche, as well as quotation and criticism would indeed seriously impair their freedom of speech. It remains to be seen how this is going to be implemented in practice: screening algorithms obviously are not designed to identify whether 'blacklisted' content (i.e. content that they should prevent from uploading) is used for parody or criticism. If a human reviews and assesses the content, then according to which standards (given that parody cases regularly require to be decided in court)? How long will it take (in a world where, when it comes to criticism and parody, sometimes minutes matter)? Finally, the research exception is not listed among the exceptions that users of online content-sharing services may rely upon, so it seems that research purposes (regardless of how broadly they are defined in the applicable law) cannot be an excuse (at least not a priori) for uploading content in online content-sharing services.

Paradoxically the new framework, targeted at huge international OCSSPs like YouTube, will likely provide them with a competitive advantage over smaller rivals. Compliance with the new obligations would require very significant means - means that large OCSSPs may have, but not necessarily their smaller competitors (despite the mechanisms introduced to protect startups - art. 17(6)). It remains to be seen how these new rules will transform the Web.

\section{Possible Impact of the New Framework on CLARIN Centres}

CLARIN Centres are faced with the difficult task of balancing between the goal of providing quality content and avoiding excessive legal burdens related to liability for the content. Therefore, they should aim at organising their functioning in such a way as to preserve 'neutrality' with regards to the language resources that they host, and not exercising (excessive) control over them in order not to lose the Safe Harbour privilege of the e-Commerce Directive. The national interpretation of the 'neutrality' criterion should be taken into account by each consortium individually. However, under the new legal framework the difficulty does not stop here. As demonstrated above, the new framework regarding liability of OCSSPs is particularly strict and complex, to the point of potentially having a chilling effect on online content-sharing services.

According to art. 2(6) of the DSM Directive, some categories of Service Providers are expressly excluded from the definition of OCSSPs. This is the case of non-for-profit online encyclopaedias (such as Wikipedia), 
open source software developing and sharing platforms (such as GitHub), online marketplaces (such as OLX or even, arguably, Amazon) as well as "not-for-profit educational and scientific repositories".

It seems that most CLARIN repositories are indeed concerned by this last exclusion, and so they are not OCSSPs and can still qualify for the liability limitation for hosting providers in the e-Commerce Directive.

However, the situation becomes more complicated if a CLARIN repository is used for some sort of commercial (for-profit) purposes, such as charging (even only some categories of users) for access, or use in public-private partnerships. Sometimes it can indeed be very difficult to draw a line between what is 'not-forprofit' and 'for-profit', but crossing this invisible line may have significant consequences as far as liability is concerned.

It may be tempting for CLARIN repositories to use contractual clauses to shield themselves from liability. Indeed, it is good practice to include in the Deposition License Agreement (DLA) an appropriate warranty or liability clause by which the depositor guarantees that the deposition is made lawfully, and assumes liability for damages caused by the content. However, such clauses may be of limited practical significance - they do not liberate the hosting provider from any obligations vis-à-vis the right holder (who is often a legal entity and not a registered user of the repository, so it has no contractual relation with the repository), and the depositor may simply not be solvable enough to compensate the hosting provider for resulting damages. Furthermore, the presence of such clauses in the DLA may have a chilling effect on some potential depositors. It is therefore erroneous to think that the liability conundrum can be solved with simple contractual mechanisms, if they are not accompanied with appropriate technical and organisational measures, such as noticeand-take down procedures, and diligent risk management. Similarly, any formal declaration that the repository remains neutral and passive with regards to the hosted content will not shield against liability, if it does not correspond to reality.

The purpose of this paper is to stimulate debate between CLARIN centres, the Board of Directors and legal experts on how CLARIN repositories should be organised in order to best fit within the existing legal framework regarding liability of service providers. Such a debate does indeed seem necessary.

\section{References}

Christina Angelopoulos. 2017. On Online Platforms and the Commission's New Proposal for a Directive on Copyright in the Digital Single Market.

Directive 2000/31/EC of the European Parliament and of the Council of 8 June 2000 on certain legal aspects of information society services, in particular electronic commerce, in the Internal Market.

Directive (EU) 2019/790 of the European Parliament and of the Council of 17 April 2019 on copyright and related rights in the Digital Single Market and amending Directives 96/9/EC and 2001/29/EC.

European Parliament. 2017. Providers Liability: From the eCommerce Directive to the future. In-Depth Analysis for the IMCO Committee. Available at: http://www.europarl.europa.eu/RegData/etudes/IDAN/ 2017/614179/IPOL_IDA(2017)614179_EN.pdf. Accessed 10.02.2020.

Pawel Kamocki. 2014. The Liability of Service Providers in e-Research Infrastructures. Killing the messenger? Proceedings of the 9th Language Resources Evaluation Conference, Reykjavik.

Julia Reda. Official Blog, https://juliareda.eu/eu-copyright-reform/censorship-machines/. Accessed 10.02.2020.

Patrick van Eecke, Online Service Providers and Liability: A Plea for a Balanced Approach. Common Market Law Review, 1455:48. 